\title{
The Design and Implementation of financial Management Information System of the Company
}

\author{
Min Zhou \\ \{ zhouminwh@126.com\} \\ Faculty of business, Wuhan Polytechnic, Wuhan 430074, China
}

\begin{abstract}
In this paper, on the background of the development of TF Investment Corporation Fund and accounting management system, on the development status of domestic and foreign investment holding management model of enterprise group and similar systems based on the survey, according to the TF investment corporation strategic financial management, financial organization structure and financial accounting business process characteristics, analyzes the suitable to support TF group companies to invest fund and accounting management business model, eliminate information screen, control in the process of "centralized management mode", TF investment group company finance management system to solve the main problem is proposed, system as a whole, system requirement analysis and system design. The TF investment group company management information system the basic realization of the investment company and affiliated investment holding between the project company financial accounting information integration, information remote management, data analysis and processing of the application and operational support function, in order to speed up the capital turnover and the integration of resources, enhance the core competitiveness of the company to a positive role in promoting.
\end{abstract}

Keywords: TF investment group company; finance and accounting management; information system; system design

\section{Introduction}

Enterprise's strength is not only the material, equipment and funds have, more important is the use of information resources and human resources. As a large scale and business scope of the vast investment holding enterprise, facing the cause business scale, diversification, investment and financing behavior caused by more complex business requirements, information resource use efficiency and thus improve the efficiency of human resources to improve the overall capital and resource use efficiency, reduce business risk, enhance competition ability is more important. As an important part of enterprise information construction, enterprise fund and accounting management informationization construction of enterprise reform important blood fund and accounting work process, greatly improve financial management efficiency and reduce operation cost of the whole enterprise [1], improve enterprise management level plays an important role. The development and construction of enterprise financial management information system is the concrete realization form of enterprise funds and accounting information. With the rapid development of network technology, modern information technology is changing people's study, work and life style 
profoundly. Through the use of information technology implementation of enterprise fund and accounting management informationization construction, more scientific, more quickly, more accurate to develop and use of funds of enterprises accounting information resources, enhance enterprise funds to co-ordinate the ability, improve leadership decision-making ability, to enhance the competitiveness of enterprises has important significance. Investment Group Ltd is a type of investment holding enterprise group, this type of company by holding shares of other companies and to achieve decisive vote to participate in the company's capital controls, mainly engaged in is the property management activities. Its management and management in addition to the characteristics of general enterprises, but also has its own unique characteristics, these unique characteristics of its information system to determine the special requirements.

\section{System planning}

TF investment group financial accounting management information system strategic planning is an important part of the group's financial strategic planning, is about the group's financial management information system of the long-term development of the planning. Through making plans, find out the existing problems, and identify the tasks that must be completed to achieve the goal of enterprise management information system, promote the application of information system, and bring more economic benefits. TF investment group is a company engaged in the field of real estate investment holding type enterprise group. The main business is the use of its own funds and funds for the acceptance of real estate development investment, the high growth of real estate business strategic investment, as well as comprehensive investment banking business. The predecessor of the company is building engineering construction enterprise, business has experienced several upheavals decoration, elevator installation and renovation, building materials supply and marketing, building construction, real estate project development to grow for today's real estate investment holdings group. Financial strategy is an important part of the company strategy, and it is a long-term course for the company to match the company's strategy. The company's financial strategy of the need to develop with the company activity in the environment match and full consideration of the enterprise's ability of utilizing resources, including material resources, market resources and human resources, fully integrated with the development trend of the enterprise comprehensive decision-making Zhu. In recent years, the rapid development of the domestic real estate industry, called by capital group of companies facing rare opportunities for development, company by virtue of their years of experience in real estate related industry investment, operating performance continues to rise, Analysis Investment Group Corporation and its subsidiary holding company internal and external environment factors based on, the company developed a general strategy in the regional market to increase project development efforts and increase the Qi Ren in the market share and brand awareness [2], profits remained a certain proportion of growth become regional real estate industry Pai head soldier and has a unique competitive advantage in the real estate investment holding group. 


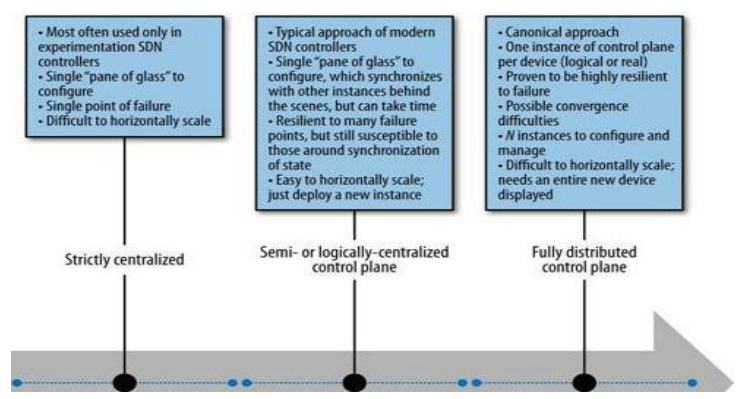

Fig. 1. Schematic diagram of distributed system

\section{System Design}

TF investment group, a subsidiary of item company scattered in Harbin, Shenyang, Guangzhou, Sanya and other places, a large geographical span, diversified business form. Based on the need to standardize the management of the investment holding company capital accounting business, investment corporation fund and accounting information management applications both to achieve accounting, financial management and analysis, financial decision support etc. single level business processing, but also to achieve investment holding company of subordinate unified definition of project fund and accounting information of unified planning, process, information real-time understanding and monitoring, the level of the company's decision support. Centralized control mode through comprehensive data planning, the establishment of a unified, standard data system, the definition of a clear data interface, the greatest degree of unified management of data. In combination with the actual situation of TF investment group company, the design principles of TF investment group financial accounting management information system should meet the following requirements. The security of the system will be the most important factor in the design of the system. In addition to the operating system, network communication platform and database level provides a reliable security measures, investment group company fund and accounting management information system design must also ensure the security of user data in the storage, transmission, enquire etc. in the process of, to prevent illegal users from unauthorized modification and manipulation of data [3].

\subsection{Expected Target of the System}

Through comprehensive survey of TF Investment Corporation Fund and accounting business analysis, TF investment group eventually established through the establishment of a is safe and reliable, has good openness and expansion of fund and accounting management information system, improve the scientific level of business management of the group company, improve the overall economic benefits of the group, to provide funds and resources guarantee for the overall development of company. TF investment group the centralized fund and accounting management information, the use of the system object is investment holding group company and the characteristics of this kind of enterprise is to rapid expansion of the scale, industrial diversification and rapid expansion, anus fabric structure changes rapidly. At 
the same time information is certain base mesh system heterogeneous, the construction to take one to take the overall planning, the distribution of the implementation of the strategy. Therefore, 'Investment Corporation Fund and accounting management information system design requirements of the overall structure of the system is a three-dimensional, dynamic, integrated architecture design, although the project is only the design of capital, while management system, but to and to the future application of the overall design, to adapt to the company management improvement and system should be expanded. Need to have the support of the transverse application development and support to enhance the management of longitudinal two scalable attribute, the overall architecture of the system must be to meet the requirements of flexible, also face the business and financial personnel two human Tun many different levels and the different roles of the management personnel to provide services [4].

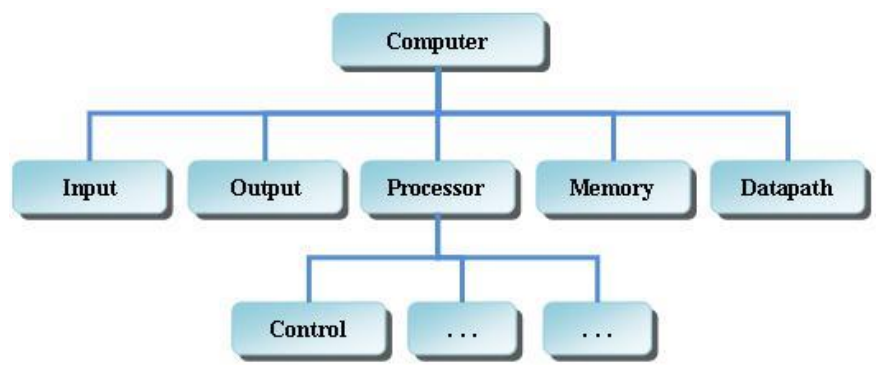

Fig. 2. System function structure diagram

\subsection{System Network Architecture}

TF group companies to invest fund and accounting management information system using centralized distributed architecture, the assets management system and financial accounting system data for all the focus to the Corporation, the holding subordinate company's server as a front-end, deployment of a portion of the application to the subsidiary shares of the company's front-end control, when call this part of the application is actually running on the local server, can improve the performance and reduce the pressure of the group company server. In order to ensure the system safety and efficiency, system of the database server data center and work area all the dual system, the data storage medium using disk array with high performance and data access using dual high-speed optical switches to improve the access speed. System using the structure, disk arrays, tape libraries constitute storage pool, the server is connected to the storage pool via optical switches and realize the storage device of the cross platform, the unified management of the storage device, storage capacity of dynamic allocation. The internal and external users of the bureau network access to the application server through the bureau network and the Internet.

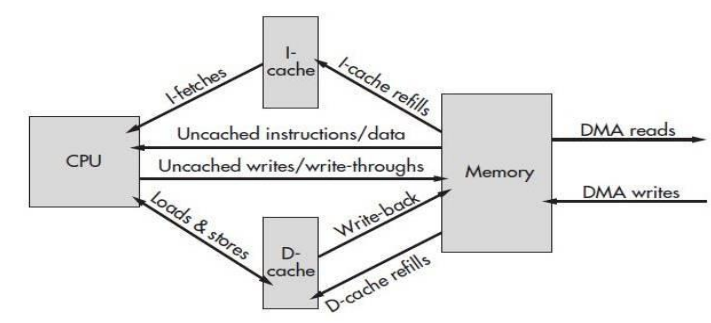


Fig. 3. System network architecture diagram

\subsection{Detailed Design Supplementary Documentation}

Use case view can well describe the overall structure of the system, and supplementary documents for detailed design mainly according to the interface of the operating system process on a specific business use case realization were describe their mutual support can well solve the software developers get task detailed information problems. Under the "foreign fine design document making auxiliary parts", explains the structure and content of the detailed design document. Vouchers according to the audited original documents fill, is based on direct registration books. The "single function" process to cover their business vouchers. Many of the features of single function, can be used to facilitate and simplify the operation. Accounting documents and business data in the design to achieve integration, business data can be from the secondary system, input, can also be entered from the document, the result is exactly the same. Business system data can be self into accounting documents and in the general ledger system does not allow to revise, when changing the raw business data, vouchers to make the corresponding changes. According to the description of the different use cases of the audience can be divided into business use cases and system use cases. For users of the system, focusing on business process description, but multiple description implementation details is the business use case and from the system developer, in business use case based on further according to the system architecture design and a variety of constraints refinement, lay particular emphasis on explaining the system function structure relationship of business needs and its realization is the system use case. ' the first capital corporation fund and accounting management information system adopted detailed design method of Sichuan is in the business use case, and the architecture design of climbing foundation hill, through systematic thinking and design the business use cases into detailed system use cases and use case documents and hand drawing, gallery and data base design. This section is a case study of the process of fine design in the case of the two Wuchuan night center of the red of the sunset and the establishment of the [5].

\section{Conclusion}

Investment holding enterprises is an important subject of national economic competitiveness, and a large number of investment holding companies have been produced in China in recent years. But in the rapid development and expansion of the process of this kind of enterprise is also facing international competition, industry consolidation and other a series of pressure, of which the main or from the pressure that the competitiveness of the upgrade, the healthy growth of their own problems, how to maintain effective control in the process of rapid development has become a key. To solve these problems, information technology is the key, and the group oriented group financial system is the best entry point. The for investment group company fund and accounting work actual situation by structured design method, combined with investment holding enterprise financial organization structure, develop the fund and accounting management module, convenient for management personnel real-time input data, query data and modify data. 


\section{References}

[1] Liao Dequan. The design of the network office automation system based on. Web shopping mall modernization. No. 26. (2014)

[2] Wang Kai. From the accounting computerization to the financial information of. Chinese information management. No. 12. (2015)

[3] Liang Lijin, Zhou Haibo. The application and risk analysis of ERP financial subsystem in China. productivity research. No. 08. (2015)

[4] king Zhou Xiaojuan. WEB, B/S database technology based on. Journal of Xi'an External affairs Institute. No. 01. (2012)

[5] Yang Yan, Wei Ren Yong. Enterprise MIS system development technology based on. Internet computing technology and automation. No. 04. (2011) 